\title{
Relationship between Leadership Self-Efficacy and Leadership Effectiveness of First-Line Nurse Managers
}

\section{Ebstam Abou*}

Department of Nursing, Alexandria University, Egypt

*Corresponding author: Ebstam Abou, Department of Nursing, Alexandria University, Egypt, Tel: +20 3 5921675; E-mail: ebtsam_ss@hotmail.com

Received date: October 04, 2017; Accepted date: October 10, 2017; Published date: October 24, 2017.

Copyright: 2017 ( ) Abou E. This is an open-access article distributed under the terms of the Creative Commons Attribution License, which permits unrestricted use, distribution, and reproduction in any medium, provided the original author and source are credited.

\begin{abstract}
Background: Today, nursing leaders face unprecedented challenges as healthcare organizations struggle to adapt to ever-accelerating rates of change both internally with the external environment in which they are embedded. The connection between leadership self-efficacy and leadership effectiveness may be critical to find new ways of selecting and developing leadership in healthcare organizations. Greater understanding is needed regarding how leaders' efficacy beliefs interact with their broader self-concept and effectiveness to increase the adaptability across numerous challenges, roles, and performance contexts.
\end{abstract}

Purpose: This study aimed to investigate the relationship between leadership self-efficacy of first-line nurse managers and their leadership effectiveness.

Methods: Design and setting: A descriptive co-relational research design was conducted at all inpatient medical and surgical care units at Alexandria Main University Hospital. Subjects included; all first-line nurse managers $(\mathrm{N}=37)$; all staff nurses $(\mathrm{N}=400)$ and all nursing supervisors $(\mathrm{N}=14)$ working in the previously mentioned units. Leadership Self-Efficacy Inventory was used by first-line nurse managers to assess their leadership self-efficacy, and Leadership Effectiveness Scale, a $360^{\circ}$ feedback instrument was used to assess leadership effectiveness of first-line nurse managers from different sources.

Results: The findings of this study revealed a significant positive correlation between overall leadership selfefficacy of first-line nurse managers and their leadership effectiveness $(r=0.190, p=0.000)$. However, a significant difference was found among first-line nurse managers, staff nurses and nursing supervisors regarding their overall perception of leadership effectiveness of first-line nurse managers $(F=19.69, p=0.000)$.

Conclusion and recommendation: Leadership self-efficacy is considered a useful and important strategy for improving leadership effectiveness, staff improvement and empowerment. Continuous educational programs that focus on advancement and challenging situations in leadership, strategic issues, change management, work unit management, should be provided for first-line nurse managers in order to enhance and support their self-efficacy and effectiveness in their leadership role and meeting different work expectations.

Keywords: Leadership self-efficacy; Leadership effectiveness; Firstline nurse managers

\section{Introduction}

Nursing leadership at both organizational and unit levels has a major influence on professional nursing practice. The professional practices of staff nurses may depend in part on first-line nurse managers' ability to provide an environment more conducive to professional practice [1]. First-line nurse manager is described as the pivotal point in health care delivery system [2]. He/She has a critical role to play in providing ongoing leadership and accountability for quality care issues and quality improvement efforts $[3,4]$. First-line nurse manager role as a leader is critical to managing patients' care toward optimal clinical outcomes. Changing patterns of care delivery and constrained resources require nursing managers as leaders to be responsive, demonstrate flexibility, know the concepts and principles of leadership, demonstrate competence in the role of leader, and make the interpersonal connections needed to be successful in this role $[5,6]$.
Moreover, nursing leaders face unprecedented challenges as health care organizations struggle to adapt to ever-accelerating rates of change both internally with the external environment in which they are embedded. Such change challenges include the knowledge, skills and abilities of leaders, and perhaps even more important, the selfconceptualizations of their leadership capabilities and psychological resources as their leadership self-efficacy to meet the ever-increasing demands of their roles [7]. The concept of self-efficacy was defined by Bandura as 'the belief that one has personal capabilities and resources to organize and execute courses of action to attain the designated goals. Individual's sense of self-efficacy can play a major role in how one approaches goals, tasks and challenges [8]. The significant influence of self-efficacy on individual performance has been wellestablished, and the positive results have been extended to the leadership area [9]. Also, leadership researches have concluded that leaders' self-efficacy may be one of the most ingredients in successful leadership and team performance [10]. Since, leadership realize the importance of self-efficacy role in its development so literature prove 
that relationship between leadership and self- efficacy generating new concept called leadership self-efficacy $[11,12]$.

\section{Conceptual framework}

Paglis and Green conceptually defining Leadership Self-Efficacy (LSE) as "a person's judgment that he/s can successfully exert leadership by setting a direction for the work group, building relationships with followers in order to gain commitment to goals, and working with them to overcome obstacles to change" [13]. Building upon the work of Paglis and Green and their definition of leadership self-efficacy, Anderson et al. built a framework for assessing the relationship between leader's beliefs about their own abilities (leadership self-efficacy) and their job performance [14].

Anderson taxonomy of leadership self-efficacy identified 18 components/dimensions for leadership self-efficacy. Each component of the LSE was believed to represent a constellation of beliefs about leadership attributes that managers see as covarying within themselves. Such constellations of LSE beliefs may be interpreted as underlying belief structures regarding leadership strengths. These components are; Change, Drive, Solve, Build, Act, Involve, Self-Discipline, Relate, Oversee, Project Credibility, Challenge, Guide, Communicate, Mentor, Motivate, Serve, Convince, and Know [14]. On the other hand, Leadership Effectiveness can be defined as "the ability to obtain the resources necessary to accomplish established goals of the institution by garnering the cooperation of others" [15]. Leadership effectiveness has been described also as associating a level of confidence in the knowledge, skills, and abilities with leading others [16]. According to Anderson et al. there are nine dimensions for leadership effectiveness namely; Relational, Impartial, Technical, Creative, Directive, Tenacious, Empowering, Influential, and Strategic leadership [14].

\section{Significance of the study}

Although leadership self-efficacy (LSE) has become very recently a focus of empirical research, there is a growing evidence demonstrating its capacity to predict relevant work outcomes such as; motivation to lead, organizational commitment, individual and organizational performance and leadership effectiveness. As would be expected, the most popular subject of interest in research has been the leadership self-efficacy relationship with leadership effectiveness. Anderson et al. recognized the need for further understanding of the degree to which managers' conception of their own skills affects their work [14]. One research stream especially relevant in today's challenging management climate explores the interplay between self-efficacy and leadership in organizations specifically, how do managers' judgments about their leadership capabilities affect their behaviours. Using self-efficacy in leadership research in a manner consistent with its theoretical foundation requires careful examination and clarification in an empirical study. So, it's recommended to conduct research on leadership self-efficacy and clarify how the findings can be used to improve managerial effectiveness.

Studies in USA and European countries handled leadership selfefficacy and leadership effectiveness and their relationship with each other [9-16]. These studies recommended for further investigation of this relationship to find or innovate ways to apply what has been learned about leadership self-efficacy to improve leadership effectiveness, and developing future leaders, placing them mindfully in superior-subordinate dyad and taking steps to create high leadership self-efficacy climate. However, studies done in Egypt in this field were limited to; assessment of the factors associated with leadership styles, effect of leadership training program for head nurses on their leadership style and their nurse subordinates' satisfaction $[17,18]$. It is noteworthy that no study examined the role of leadership self-efficacy and its relationship with the effectiveness of leadership in work setting specifically in nursing field. Hence, it is hoped that such study will provide knowledge to improve leadership performance and effectiveness of nurse managers' work that will be reflected in their work setting, and nursing generally through developing and extending leadership self-efficacy and effectiveness among them.

\section{Aim of the study}

The aim of this study was threefold to: (a) investigate the relationship between leadership self-efficacy of first-line nurse managers and their leadership effectiveness, (b) identify how do firstline nurse managers perceive their leadership self-efficacy, and, (c) determine how does leadership effectiveness of first-line nurse managers evaluated from different sources including (self-assessment, subordinate assessment, and supervisors' assessment).

\section{Research questions}

- What is the relationship between leadership self-efficacy of firstline nurse managers and their leadership effectiveness?

- How do first-line nurse managers perceive their leadership selfefficacy?

- How does leadership effectiveness of first-line nurse managers evaluated from different sources including (self-assessment, subordinate assessment, and supervisor's assessment)?

\section{Materials and Methods}

\section{Research design and setting}

A descriptive co-relational research design was conducted in all inpatient medical and surgical care units at Alexandria Main University Hospital (N=37).

\section{Subjects}

\section{The subjects of the study comprised:}

- All first-line nurse managers (head nurses) working in medical and surgical in-patient care units and available at the time of data collection $(\mathrm{N}=37)$ were included to assess their leadership's selfefficacy and as well as their leadership effectiveness. They were classified into; 16 head nurses working at surgical care units, and 21 head nurses working at medical care units.

- All staff nurses who worked with first-line nurse managers in the previously mentioned units and available at the time of data collection $(\mathrm{N}=400)$ were included to assess leadership effectiveness of their first-line nurse managers. They were classified into; 204 nurses working at surgical care unit, and 196 nurses working at medical care units.

- All nursing supervisors $(\mathrm{N}=14)$ were included to assess leadership effectiveness of first-line nurse managers working under their supervision in the previously mentioned units. They were classified into; 4 supervisors responsible for surgical care units, and 5 supervisors responsible for medical care units and 5 supervisors responsible for both. 


\section{Study tools}

Leadership Self-Efficacy Inventory, developed by Anderson et al. was used by first-line nurse manager to assess their leadership selfefficacy and indicate their ability to perform each item [14]. It consists of 88 -items grouped into 18 sub-scales including the following: change (seven-items), drive (six-items), solve (five-items), build (five-items), act (four-items), involve (six-items), self-discipline (four-items), relate (six-items), oversee (four-items), project credibility (five-items), challenge (five-items), guide (seven-items), communicate (five-items), mentor (three- items), motivate (five-items), serve (five-items), convince (three-items), know (three- items). Responses were measured on 7-point Likert scale ranged from $(7)=$ certain to do, to $(1)=$ unable to do. The higher the score, the more self efficous nurse manager.

Leadership Effectiveness Scale (Multi-source assessment rating scale) developed by Anderson et al. [14]. It is a $360^{\circ}$ feedback instrument that used to assess leadership effectiveness of first-line nurse managers from different sources including (self-assessment/firstline nurse managers, subordinates assessment/ staff nurses, and nursing supervisors' assessment). Respondents were asked to indicate how effective first-line nurse managers were in performing each item. It consisted of 88- items grouped into 9 sub-scales namely: relational leadership (16-item), impartial leadership (15-items), technical leadership (nine-items), creative leadership (12-items), directive leadership (eight- items), tenacious leadership (nine-items), empowering leadership (eight-item), and influential leadership (sixitems), and strategic (five-items). Responses were measured on 7-point Likert scale ranged from (7) =high effective, to (1) =low effective. The higher the score, the more effective nurse manager. In addition, demographic data form was developed for first-line nurse managers, staff nurses and as well as nursing supervisors. It included questions related to; age, marital status, year of experience, and educational qualifications.

\section{Validity and reliability}

The study questionnaires were translated into Arabic and examined for translation and content validity and relevance to be suited for Egyptian culture by 5 experts in the field of study from different academic departments at the Faculty of Nursing, Alexandria University. Accordingly, some statements were restated. Also, a pilot study was done on $10 \%$ of study subjects that were excluded from the study participants to; check and ensure clarity and applicability of the tool; identify obstacles and problems that may be encountered during data collection. Accordingly, no modification was done. In addition, questionnaires were examined for reliability to measure the internal consistency of the items using Cronbach's alpha coefficient test. The questionnaires were proved reliable where $\alpha=0.984$ for Leadership SelfEfficacy Inventory and 0.980 for Leadership Effectiveness Scale.

\section{Data collection}

Written approval was obtained from administrative personnel in the identified setting to collect the necessary data. Data were collected using self-administered questionnaires which distributed individually for study participants in their work setting and needed instructions were given before the distribution of the questionnaires. Each study subject consumed 30 minutes to fill out the questionnaires. It took a period of four months to collect data.

\section{Data analysis}

Data were coded and entered the statistical software program SPSS, version 19. Frequency and percentages were used for describing demographic characteristics. Arithmetic mean and standard deviation (SD) was used as measures of central tendency and dispersion, respectively, for quantifying variables under the study. Student's t-test was used to compare between two means, and one-way analysis of variance (ANOVA) (F) test was used to compare the mean scores among more than two groups. Pearson correlation coefficient analysis (r) was used to test the nature of the relationship between the study variables. All statistical analyses were done using 2 -tailed tests and $\alpha$ error of 0.05 . P-value $\leq 0.05$ considered to be significant.

\section{Results}

\section{Demographic characteristics}

Table 1 illustrates that, approximately $50 \%$ of all study subjects worked in each of the medical and surgical care units. About one third of all study subjects (33.3\%) had from $40-49$ years old. The highest percentages $(70.9 \%)$ of them were married, and $34.4 \%$ had from $20-29$ years of work experience. The highest percentage of first-line nurse managers (48.65\%) and nursing supervisors (64.29\%) had a bachelor degree of nursing, while, the majority of staff nurses (89.5\%) had a diploma of secondary technical nursing school. Additional information on demographic characteristics of the participants can be found in Table 1.

\begin{tabular}{|l|l|l|l|l|l|l|l|l|l|l|}
\hline & $\begin{array}{l}\text { First line nurse managers } \\
\text { (N=37) }\end{array}$ \\
Demographic \\
characteristics
\end{tabular}


Citation: Abou E (2017) Relationship between Leadership Self-Efficacy and Leadership Effectiveness of First-Line Nurse Managers. Arts Social

Page 4 of 9

\begin{tabular}{|c|c|c|c|c|c|c|c|c|}
\hline $40-49$ & 16 & 43.24 & 126 & 31.5 & 8 & 57.14 & 150 & 33.3 \\
\hline $50-59$ & 16 & 43.24 & 51 & 12.75 & 6 & 42.86 & 73 & 16.2 \\
\hline \multicolumn{9}{|l|}{ Marital Status } \\
\hline Single & 2 & 5.41 & 99 & 24.75 & - & - & 101 & 22.4 \\
\hline Married & 32 & 86.49 & 277 & 69.25 & 11 & 78.57 & 320 & 70.9 \\
\hline Widow/divorced & 3 & 8.11 & 24 & 6 & 3 & 21.43 & 30 & 6.7 \\
\hline \multicolumn{9}{|l|}{ Years of Experience } \\
\hline$<10-$ & - & - & 64 & 16 & - & - & 64 & 14.2 \\
\hline $10-19$ & 11 & 29.73 & 135 & 33.75 & 3 & 21.43 & 149 & 33 \\
\hline $20-29$ & 11 & 29.73 & 138 & 34.5 & 6 & 42.86 & 155 & 34.4 \\
\hline $30-39$ & 15 & 40.54 & 63 & 15.75 & 5 & 35.71 & 83 & 18.4 \\
\hline \multicolumn{9}{|l|}{ Degree of Education } \\
\hline Post graduate/others & - & - & 2 & 0.5 & 2 & 14.29 & 4 & 0.89 \\
\hline Bachelor of nursing & 18 & 48.65 & 11 & 2.75 & 9 & 64.29 & 38 & 8.4 \\
\hline *Dip. THI & 4 & 10.81 & 29 & 7.25 & 3 & 32.43 & 36 & 8 \\
\hline${ }^{* *}$ Dip STNS & 15 & 40.54 & 358 & 89.5 & - & - & 373 & 82.7 \\
\hline
\end{tabular}

Table 1: General demographic characteristics for the study subjects.

First-line nurse managers' perception of their leadership selfefficacy

Table 2 shows the overall mean score for leadership self- efficacy as perceived by first-line nurse managers $(5.3 \pm 1.46)$ which indicates a high level of perceived leadership self-efficacy. In addition, the highest mean was related to the dimensions of; communicate $(5.5 \pm 1.74)$, and project credibility $(5.5 \pm 1.60)$. While, the lowest mean score was related to the change dimension of leadership self-efficacy $(4.8 \pm 1.69)$. Moreover, this table reveals that there is no significant difference between first-line nurse managers in surgical and medical care units regarding their perception of leadership self-efficacy $(t=0.192$, $\mathrm{p}=0.849$ ). The same trend of result was reflected in all dimensions of leadership self-efficacy.

\begin{tabular}{|c|c|c|c|c|c|c|}
\hline \multirow[t]{2}{*}{ S. No } & \multirow{2}{*}{$\begin{array}{l}\text { Dimensions of Leadership self- } \\
\text { Efficacy }\end{array}$} & \multicolumn{2}{|c|}{ First-line Nurse Managers(N=37) } & \multirow{2}{*}{$\begin{array}{l}\text { Overall Mean } \pm \\
\text { S.D }\end{array}$} & \multirow[t]{2}{*}{$\mathrm{t}$-Value } & \multirow[t]{2}{*}{ p -Value* } \\
\hline & & $\begin{array}{l}\text { Surgical units }(n=16) \text { Mean } \pm \\
\text { S.D }\end{array}$ & $\begin{array}{l}\text { Medical units }(\mathrm{n}=21) \text { Mean } \pm \\
\text { S.D }\end{array}$ & & & \\
\hline 1 & Change & $4.7 \pm 1.20$ & $4.9 \pm 1.20$ & $4.8 \pm 1.69$ & 0.343 & 0.734 \\
\hline 2 & Drive & $5.3 \pm 0.99$ & $5.5 \pm 1.27$ & $5.4 \pm 1.61$ & 0.615 & 0.543 \\
\hline 3 & Solve & $5.1 \pm 1.20$ & $5.2 \pm 1.27$ & $5.1 \pm 1.62$ & 0.112 & 0.911 \\
\hline 4 & Build & $5.2 \pm 1.11$ & $5.1 \pm 1.29$ & $5.1 \pm 1.70$ & 0.261 & 0.795 \\
\hline 5 & Act & $5.2 \pm 1.15$ & $5.2 \pm 1.35$ & $5.2 \pm 1.77$ & 0.058 & 0.954 \\
\hline 6 & Involve & $5.2 \pm 0.91$ & $5.3 \pm 1.34$ & $5.2 \pm 1.61$ & 0.395 & 0.695 \\
\hline 7 & Self-Discipline & $5.4 \pm 1.29$ & $5.3 \pm 1.35$ & $5.3 \pm 1.86$ & 0.211 & 0.834 \\
\hline 8 & Relate & $5.4 \pm 1.22$ & $5.3 \pm 1.33$ & $5.3 \pm 1.80$ & 0.282 & 0.779 \\
\hline 9 & Oversee & 5.41 .16 & $5.3 \pm 1.42$ & $5.3 \pm 1.83$ & 0.336 & 0.739 \\
\hline
\end{tabular}


Citation: Abou E (2017) Relationship between Leadership Self-Efficacy and Leadership Effectiveness of First-Line Nurse Managers. Arts Social

Page 5 of 9

\begin{tabular}{|c|c|c|c|c|c|c|}
\hline 10 & Project Credibility & $5.7 \pm 0.95$ & $5.3 \pm 1.29$ & $5.5 \pm 1.60$ & 1.028 & 0.311 \\
\hline 11 & Challenge & $5.5 \pm 1.17$ & $5.3 \pm 1.45$ & $5.4 \pm 1.86$ & 0.403 & 0.689 \\
\hline 12 & Guide & $5.7 \pm 1.05$ & $5.2 \pm 1.21$ & $5.4 \pm 1.60$ & 1.231 & 0.226 \\
\hline 13 & Communicate & $5.7 \pm 1.26$ & $5.3 \pm 1.21$ & $5.5 \pm 1.74$ & 0.97 & 0.339 \\
\hline 14 & Mentor & $5.4 \pm 1.03$ & $5.2 \pm 1.24$ & $5.3 \pm 1.61$ & 0.548 & 0.587 \\
\hline 15 & Motivate & $5.4 \pm 0.88$ & $5.4 \pm 1.24$ & $5.4 \pm 1.52$ & 0.06 & 0.952 \\
\hline 16 & Serve & $5.4 \pm 1.06$ & 5.41 .29 & $5.4 \pm 1.66$ & 0.025 & 0.98 \\
\hline 17 & Convince & $5.1 \pm 108$ & $5.1 \pm 1.26$ & $5.1 \pm 1.65$ & 0.071 & 0.944 \\
\hline \multirow[t]{2}{*}{18} & Know & $5.3 \pm 1.36$ & $5.7 \pm 1.36$ & $5.5 \pm 1.92$ & 0.796 & 0.432 \\
\hline & Overall Leadership Self-Efficacy & $5.3 \pm 0.92$ & $5.3 \pm 1.15$ & $5.3 \pm 1.46$ & 0.192 & 0.849 \\
\hline
\end{tabular}

Table 2: First-line nurse managers' perceptions of their leadership self-efficacy in surgical and medical care units.

Differences among study subjects regarding their perceptions of leadership effectiveness of first-line nurse managers

Table 3 reveals that there is a significant difference among all study subjects including (first-line nurse managers, staff-nurses and nursing supervisors) regarding their perceptions of leadership effectiveness of first-line nurse managers $(\mathrm{F}=19.697, \mathrm{p}=0.000)$. First-line nurse managers had the highest rating and mean score $(5.8 \pm 0.81)$ in comparison to their staff nurses $(4.6 \pm 1.22)$ and nursing supervisors $(4.5 \pm 0.959)$. The same trend of result was reflected in all dimensions of leadership effectiveness with $(\mathrm{p}=0.000)$. In addition, the highest mean score of leadership effectiveness was related to Impartial leadership dimension as perceived by first-line nurse managers $(5.930$ $\pm 0.8439)$, staff nurses $(4.715 \pm 1.3562)$, and nursing supervisors (4.583 $\pm 1.0426)$. On the contrary, the lowest mean score was related to the strategic leadership dimension as perceived by first-line nurse managers (5.676 \pm 1.0613$)$, staff nurses (4.418 \pm 1.4499$)$, and nursing supervisors $(4.322 \pm 1.1032)$.

\begin{tabular}{|c|c|c|c|c|c|c|}
\hline \multirow{2}{*}{ S. No } & \multirow{2}{*}{$\begin{array}{l}\text { Dimensions of Leader ship } \\
\text { Effectiveness }\end{array}$} & \multirow{2}{*}{$\begin{array}{l}\text { First-line Nurse Managers } \\
\text { Mean } \pm \text { S.D }\end{array}$} & \multirow{2}{*}{ Staff Nurses Mean \pm S.D } & \multirow{2}{*}{$\begin{array}{l}\text { Nursing } \\
\text { Mean } \pm \text { S.D }\end{array}$} & \multicolumn{2}{|l|}{ ANOVA } \\
\hline & & & & & $\mathbf{F}$ & $\mathbf{P}$ \\
\hline 1 & Relational Leader ship & $5.894 \pm 0.8583$ & $4.704 \pm 1.3301$ & $4.457 \pm 0.9964$ & 18.988 & $.000^{* * *}$ \\
\hline 2 & Impartial Leadership & $5.930 \pm 0.8439$ & $4.715 \pm 1.3562$ & $4.583 \pm 1.0426$ & 17.409 & $.000^{* * *}$ \\
\hline 3 & Technical Leadership & $5.871 \pm 0.7850$ & $4.608 \pm 1.3708$ & $4.531 \pm 1.0413$ & 17.437 & $.000^{* \star *}$ \\
\hline 4 & Creative Leadership & $5.688 \pm 0.9205$ & $4.649 \pm 1.4364$ & $4.403 \pm 1.1114$ & 12.781 & $.000^{* * *}$ \\
\hline 5 & Directive Leadership & $5.784 \pm 0.8871$ & $4.644 \pm 1.4057$ & $4.420 \pm 1.1425$ & 15.06 & $.000^{* * *}$ \\
\hline 6 & Tenacious Leadership & $5.832 \pm 0.8234$ & $4.655 \pm 1.3988$ & $4.332 \pm 1.1170$ & 18.124 & $.000^{* * *}$ \\
\hline 7 & Empowering Leadership & $5.703 \pm 0.9183$ & $4.548 \pm 1.2975$ & $4.518 \pm 1.0821$ & 15.282 & $.000^{* \star *}$ \\
\hline 8 & Influential Leadership & $5.712 \pm 1.1081$ & $4.610 \pm 1.3821$ & $4.566 \pm 1.1442$ & 12.268 & $.000^{\star * *}$ \\
\hline \multirow[t]{2}{*}{9} & Strategic Leadership & $5.676 \pm 1.0613$ & $4.418 \pm 1.4499$ & $4.322 \pm 1.1032$ & 15.04 & $.000^{* \star *}$ \\
\hline & Overall Leadership Effectiveness & $5.8 \pm 0.81$ & $4.6 \pm 1.22$ & $4.5 \pm 0.959$ & 19.697 & $.000^{\star * *}$ \\
\hline
\end{tabular}

Table 3: Differences among study subjects regarding their perceptions of leadership effectiveness of first-line nurse managers. 


\section{Correlation between leadership self-efficacy and leadership effectiveness of first-line nurse managers}

Table 4 reveals generally there is a significant positive correlation between overall leadership self-efficacy of first-line nurse managers and their leadership effectiveness $(r=0.190, p=0.000)$. Also, a significant positive correlation was found between leadership self- efficacy and leadership effectiveness as perceived by first-line nurse mangers $(r=0.65, p=0.000)$ and staff nurses $(r=0.222, p=0.000)$, while there is no significant correlation between leadership self-efficacy of first-line nurse mangers and their leadership effectiveness as perceived by nursing supervisors $(\mathrm{r}=-0.031, \mathrm{p}=0.746)$.

\begin{tabular}{|c|c|c|c|}
\hline Variables & First-Line Nurse Mangers & Staff Nurses & Nursing Supervisors \\
\hline Leadership Self-Efficacy & $r=0.651$ & $r=0.222$ & $r=-0.031$ \\
\hline Leadership Effectiveness & $\mathrm{p}=0.000^{* * *}$ & $\mathrm{p}=0.000^{* * *}$ & $p=0.746$ \\
\hline \multicolumn{4}{|l|}{ Overall Leadership Effectiveness } \\
\hline Overall leadership Self Efficacy & $\begin{array}{l}r=0.190 \\
p=0.000^{* * *}\end{array}$ & & \\
\hline
\end{tabular}

Table 4: Correlation between leadership self-efficacy and leadership effectiveness of first-line nurse managers as perceived by study subjects.

\section{Discussion}

Many research findings suggested that, enhancing leadership selfefficacy perception may be a useful strategy for improving leaders' effectiveness [9,14-16]. LSE has not only been associated with higher levels of performance for individual leaders, however, it has also been linked to higher levels of staff performance.

Supporting this view, the present study revealed a significant positive correlation between overall leadership self-efficacy of first-line nurse managers and their leadership effectiveness. This relationship indicated that increasing in leadership self-efficacy of first-line nurse managers could result in increasing their leadership effectiveness. Also, this finding was reflected in the positive relationship between the majorities of leadership self-efficacy dimensions with all dimensions of leadership effectiveness of first-line nurse managers. Leadership selfefficacy perceived to be a motivator to nurse mangers.

First-line nurse managers reported that having a sense of leadership self-efficacy gives them the opportunity to recognize their leadership skills through doing their best and believing to achieve goals under any condition to fulfill leadership role in addition to the ability to setting directions and strengthen their weakness which may lead to promote their leadership performance level and effective achievement of work responsibilities as well as overcoming the difficulties and setbacks.

This speculation could be supported by Paglis and Green who clarified that, the relationship between leadership self-efficacy and work outcomes may be explained by highly self-efficacious leaders tending to undertake more responsibilities, investing more effort in their work, and persisting longer when met with difficulties [13]. Also, Paglis and Green found that, there is a positive connection between leadership self-efficacy and measures of performance through subordinates' ratings of mangers' leadership effectiveness by attempts at driving change efforts in the work unit [13]. Leadership self-efficacy was also associated with higher organizational commitment and managers' leadership.

In the same line, Chan and Drasgow stated that, it is expected that leaders with greater leadership self-efficacy to be more effective leaders, because they are inclined to expend greater efforts to fulfill their leadership roles and to preserve longer when faced with difficulties [19]. Also Hannah et al. proposed that, greater levels of leadership selfefficacy lead to greater levels of leadership performance [7]. In addition, Hannah and Luthans stated that, leadership self-efficacy promote effective leader engagement, flexibility, and adaptability [20]. Furthermore, Lord and Brown indicated that, leadership self-efficacy affect leaders' performance by providing internal guidance and drive to create the mental state required to take on difficult and challenging tasks [21].

The result of this study is consistent with Anderson et al. found a significant and highly interpretable relationship between taxonomic structures of leadership self-efficacy and leadership effectiveness [14]. In this context, Chemers et al. concluded that leader self-efficacy, may be one of the most active ingredients in successful leadership, and team performance, and that clearly contributes to leadership effectiveness [22]. Also, McCormick and Tanguma stated that leadership selfefficacy perceptions may be a useful strategy for improving leader effectiveness [23].

Moreover, the present study revealed that first-line nurse managers perceived they had high leadership self-efficacy and effectiveness. This result could be related to their sense of responsibility at the position held in addition to their abilities and gained skills throughout their work experience which give them the sense of self-confidence and selfesteem in their managerial positions, in turn, affect positively on their perceived leadership self-efficacy and leadership effectiveness. They perceive that skills and knowledge in leadership role improved with the increased work experience. Also, they considered themselves to be role model to team members who depend on their knowledge and skills and look forward for their success.

These speculations could be explained also, in the light of what Fincher stated that, individual's accomplishments or experiences that decrease self-doubt or reinforce previous positive experiences can give an individual a sense of accomplishment, success and effectiveness [24]. Also, Burns pointed out that, the most effective way of developing a strong sense of efficacy is through mastery experiences and witnessing other people successfully completing a task [25]. 
This result goes in the same line with Burns who reported that, responsibility held at hand is considered as an important motivator which ties directly to sense of leadership self-efficacy [26]. The current result is consistent with Lucas et al. who found that, front-line nurse mangers rated themselves highly efficacious [26]. Also, McCormick and Tanguma reported high mean score for overall leadership selfefficacy score [23]. In this context, Manojlovich highlighted that, unitlevel nurse leaders who feel more efficacious in their nursing leadership roles not only have access to more power for themselves, but also provide more access to power for their staff and empower them [1].

Mainly, first-line nurse managers perceived that they can successfully exert leadership self-efficacy through their communication skills, and project credibility skills with their staff nurses, and other team members which were rated as the highest dimensions of leadership self-efficacy. First-line nurse managers reported that their managerial responsibility requires the ability to understand and interact with others and provide feedback to each other in their social environment via communicative means to increase their ability to grasp and utilize important work information which enhance their ability and confidence to influence and control their work environment. Also, they believe that through being fair, honest in their work behaviours, and providing adequate work knowledge and guiding skills they gain credibility, spiritual cooperation and teamwork.

Similarly, Kelly et al. indicated that, the more positive performance feedback received by followers via verbal, non-verbal, and written communication, the greater the increase in mangers' self-efficacy and on the other hand the managers who use the effective communication means and providing positive feedback builds situation specific selfefficacy by letting the followers know that he or she has value [27]. Moreover, Bosman reported that one of the most basic and proven ways in which self-efficacy can be improved is through verbal persuasion and a clear leadership communication function [28]. Interpersonal communication plays an important role in the decisionmaking process and for personal development of the leader.

On the contrary, change dimension was the lowest mean of leadership self-efficacy. This result might be due to their preferences to the status quo instead of change in their work roles or environment. They might fear from failure if begin any change and consider employees' resistance as an important obstacle. Similarly, Schultz stated that people often simply prefer the status quo rather than risk things [29]. They may believe that change need organizational support and employees' readiness and consider the individual differences that affect their behaviours to be successful so they may not be not persuaded that change has more benefts.

In this respect, Shah and Irani found that training and skills development in change management, pay/wages/fringe benefits, and promotion have positive impact on increasing readiness to change [30]. Therefore, there is a need for nurse managers with a coaching leadership style, strength and assertiveness in times of change to be able to lead employees in an environment where they are noticed as irreplaceable partners within the organization [31].

Moreover, it was evident that leadership effectiveness of first-line nurse managers is enhanced mainly through their identification with impartial leadership skills which rated as the highest dimension by all study subjects. Impartial leadership refers to the mangers' exhibition of behavioural decorum, making fair decisions without personal bias; considering various perspectives, showing forbearance, and maintaining stability across a wide range of work situations that enabling them to build trust and respect with others.

The finding of the study goes on the same line with McDaniel, Kenkel and Fitzwater who asserted that, a good leader is fair, respected by the others and impartial [32,33]. Equally important, he/she should maintain a public image of being fair and impartial in treating people even in times of failure, and should always make impartial judgment and decisions. Also, Harper reported that, when leaders are impartial, fair, just, unprejudiced and unbiased, impartiality produces honesty [34]. It makes a leader predictable and people know how leaders respond to issues. Also, a judge's wise, ruling and integrity flows out of impartiality. What's more, Bednarz found that, the managers to develop an open and trusting management style might require remaining impartial [35]. Before managers' deals with any employee or situation, they must avoid making rash judgments, eliminate all emotion and gather all pertinent facts.

On the other hand, strategic leadership was rated as the lowest dimension in leadership effectiveness. Strategic leaders are generally characterized by disciplined thinking concerning opportunities and threats to the organization (and its response), and an understanding of relevance of organizational culture to organizational performance. This result may be related to the lack of adequate knowledge and skills of strategic thinking and management among first-line nurse managers as well as the non-involvement of them in strategic decisions concerning their hospital. They reported that strategic leadership mostly performed in the nursing division through their top and middle levels nurse managers. In this regard, Vesterinen et al. emphasized that, when the organization drafts a new strategy and vision for the future, including nursing practice, the nurse manager at all levels is the key person to examine nursing and its resources [36].

Finally, the current study revealed that first-line nurse managers significantly perceived their leadership effectiveness higher than their staff nurses and nursing supervisors. They rated themselves as highly effective leaders in comparison to moderate rating by both their staff nurses and nursing supervisors. This difference in perception may be ascribed to the different concerns and expectations from first-line nurse managers in their leadership role. First-line nurse managers' perception may be related to their believing about themselves that they have a high leadership self-efficacy as revealed in this study. Their leadership self-efficacy might play a vital role in improving their perception about leadership abilities and effectiveness in addition to their special personality traits and qualities that they might have such as self-efficacy and experience and leadership skills beside their ability to attain goals and objectives.

However, staff nurses might perceive that first-line nurse managers focused on and loaded with managerial role which may be not invisible work to staff nurses regardless showing adequate direct care with their staff and their work. Also, nurses might feel that they are in need for more support and contact with their first-line nurse managers which enhance their relationship. In addition, workload and lack of resources might affect the work environment which diminishes the mangers' support and guidance that may be sometimes reflected negatively on the relationship between staff nurses and their nurse managers and nursing supervisors.

In this regard, Leiter assured that, managers are not visible or available all the time for their nurses [37]. They are doing tasks of management, budgeting, and meetings, and did not give enough time to the leadership practices - vision, recognition, and support for staff 
Page 8 of 9

nurses. Also, Nicklin asserted that, the increased workload with fewer resources and support for nurses and nurse mangers could affect their work and satisfaction [38].

Moreover, Rego et al. highlighted that, differences in work units, employees and situations, make no only correct leadership style and behaviours; the same result can be achieved in many ways [39]. Leaders should be emotionally intelligent to stimulate the creativity of their employees. Also, Vesterinen et al emphasized that, the nurse manager's ability to reflect on their own behaviour makes it easier to regulate and estimate their leadership practice with different employees in different situations [39]. However, it is important to remember that there are situations in which nurse managers have to make difficult decisions. Decision-making is facilitated by sufficient knowledge, work experience, and support from colleagues and supervisors.

In this context, Baxter stated that, significant challenges existed for the first-line nurse managers [40]. Those challenges were the vast responsibilities of the nurse manager role, and the constant competing priorities and demands on the nurse manager's time and the lack of knowledge and skills of new nurse managers to achieve success. These challenges can be overwhelming and nurse managers have difficulty balancing the responsibilities of their role. It is important to arrange enough updating education program to support nurse managers in their leadership work.

\section{Conclusion and Recommendations}

The most compelling finding to arise from this study is that leadership self-efficacy is considered a useful and important strategy for improving leadership effectiveness, staff improvement and empowerment. This result supports and increases the evidence of previous research results in this area. This appeared from the positive relationship between leadership-self efficacy of first-line nurse managers and their leadership effectiveness. Leadership self-efficacy of first-line nurse managers is mainly influenced by communication, and project credibility skills. Also, leadership effectiveness is influenced by their impartial leadership skills, however, change and strategic leadership skills needed to be enhanced. Moreover, first-line nurse managers significantly perceived their leadership effectiveness higher than their staff nurses and nursing supervisors.

Since, health care organizations are undergoing continuing changes, and vision should be present at all times. First-line nurse managers need new skills and knowledge to be able to manage their work. It is the health care organizations' responsibility to set up a clear vision and goals and make the successful nurse leadership possible as part of multi-professional cooperation.

\section{Several recommendations arose from this study as follows:}

- Health care organizations should draw up visions of nursing leadership in the future. Together with top nurse mangers, they should start planning education programs that focus on strategic issues and management, challenging situations and styles in leadership, change management, work unit management (e.g., economy, efficiency, and resources), and how the nurse managers consider their own wellbeing and nursing staff empowerment. Nurse managers, especially new nurse managers, need more theoretic, evidence-based education to cope with these expectations and to develop their professional abilities.
- Opportunities should be provided for enhancing first-line nurse mangers' leadership self-efficacy, such as role modeling and verbal persuasion, recognizing that through improved self-efficacy, leadership practices and behaviors may improve.

- Nursing leaders at the chief nurse executive level would have the requisite power to provide more information, support, resources, and opportunities for other nurse leaders lower in the organizational hierarchy.

- Coaching, mentoring, and peer-network support should be incorporated as part of the development program to facilitate leader-manager success in challenging assignments, leadership credibility and effectiveness.

\section{Study Strengths and Limitations}

Although the current study considered the first to examine the role of leadership self-efficacy and its relationship with the effectiveness of leadership in work setting specifically in Egyptian nursing field, the result cannot be generalized as the data were collected from one place and used self-reporting methods.

\section{Future Research Implications}

To address some of the shortcomings of the present study, future researches should be conducted to; identify what are the factors influencing leadership self-efficacy, performance and effectiveness. Also, replication of the study is needed in a wider context for generalization of findings.

\section{Ethical Considerations}

Approval was obtained from the Ethics Committee of the Faculty of Nursing, Alexandria University. The privacy and confidentiality of data were maintained and assured by getting participants' consent to participate in the research before data collection. Anonymity of participants was granted.

\section{Declaration of Conflicting Interests}

The authors declare that there is no conflict of interest.

\section{References}

1. Manojlovich M (2005) Effect of Nursing Leadership on Hospital Nurses' Professional Practice Behaviors. Journal of Nursing Management, pp: 363-371.

2. Omer E (2010) The Effect of Clinical Supervision Training Program for First-Line Nurse Managers on Quality of Care and Job Satisfaction. Unpublished Dissertation, Faculty of Nursing, Alexandria University.

3. Mrayyan M (2004) Perceptions of Jordanian Head Nurses of Variables that Influence the Quality of Nursing Care. Journal of Nursing Care Quality, pp: 276-279.

4. Lemonen T, Leino-Kilpi H, Jouko K (1996) The Quality of Intraoperative Nursing Care: The Patients'Perspectives, pp: 843-852.

5. Holm A (2014) Effective Nursing Leadership of Older Persons in the Community - A Systematic Review. Journal of Nursing Management, pp: 211-224.

6. Krugman M, Smith V (2003) The Role of Leadership to Head Nurses: Charge Nurse Leadership Development and Evaluation. JONA, pp: 284-292.

7. Hannah S, Avolio B, Luthans F, Harms P (2008) Leadership Efficacy: Review and Future Direction. The Leadership Quarterly, pp: 669-692. 
8. Bandura A (2005) The evolution of social cognitive theory, great minds in management. Oxford: Oxford University Press, pp: 9-35.

9. Paglis L (2010) Leadership Self Efficacy: Research Finding and Practical Application. Journal of Management Development, pp: 771-872.

10. Greiman B, Adengiton L (2008) Youth Leadership Development Self Efficacy: An Exploratory Study Involving a New Construct. Journal of Leadership Education, pp: 1-12.

11. McCormick M, Tanguma J, Lopez-Forment A (2002) Extending Self Efficacy Theory of Leadership: A Review and Empirical Test. Journal of Leadership Education, pp: 34-49.

12. Machida M, Schaubroeck J (2011) The Role of Self Efficacy Belief in Leader Development. Journal of Leadership and Organizational Studies, pp: 1-10.

13. Paglis L, Green S (2002) Leadership Self-efficacy and Managers' Motivation for Leading Change. Journal of Organizational Behavior, pp: 215-235.

14. Anderson D, Krajewski H, Goffin R, Jackson D (2008) Leadership Selfefficacy Taxonomy and its Relation to Effective Leadership. The Leadership Quarterly, pp: 595-608.

15. Wood R (2004) The Effect of Self-efficacy, Transformational Leadership and Trust on Leadership Effectiveness of Senior Student Affairs Officer. Published Dissertation, School of Leadership Study, Regent University.

16. Personality DA (1999) Self efficacy and managerial leadership behavior. Published Dissertation, University of Western Ontario.

17. Hamdy O, Abul Azm F, Elhawashy Z, Senble W (1985) Factors associated with leadership style, types of management and supervision that influence nurses' job satisfaction. The bulletin of High Institute of Public Health, Alexandria University, 15: 187-204.

18. Elbialy G (1995) Effect of a leadership training program for head nurses on their leadership Leadership. Unpublished Dissertation, University of Alexandria.

19. Chan K, Drasgow F (2001) Toward a theory of individual differences and leadership: Understanding the motivation to lead. J Appl Psycho 86: 481-498.

20. Hannah S, Luthans F (2008) A cognitive effective processing explanation of positive leadership: Toward Theoretical Understanding of the role of psychological capital. J Res Manage 7: 18-33.

21. Lord R, Brown D (2004) Leadership processes and follower self-identity. New Jersey: Lawrence Erlbaum.

22. Chemers M, Watson C, May S (2000) Dispositions affect and leadership effectiveness: A comparison of self-esteem, optimism, and efficacy. Personality and Social Psychology Bulletin 26: 267-277.
23. McCormick M, Tanguma J (2007) The constraining effect of pre-training leadership self-efficacy beliefs on change in posttraining leadership selfefficacy beliefs. JOLE 6: 108-126.

24. Fincher J (2008) Leadership self-efficacy for college students with learning disability. Maryland University.

25. Burns J (2010) Assessing importance of building self-efficacy to impact motivation, performance level, team effectiveness.

26. Lucas V, Laschinger H, Wong C (2008) The impact of emotionally intelligent leadership on staff nurse empowerment: The moderating effect of span of control. J Nurs Manage 8: 964-973.

27. Kelly O, Karle A, Martocchio J (2006) The impact of feedback and selfefficacy on performance in training. J Organ Behav 14: 379-394.

28. Bosman M (2011) Leader communication: Key concepts to consider.

29. Schultz A (2011) The meaning of change for a teacher at a middle school: A hermeneutic phenomenological study. Published Dissertation, Marian university.

30. Shah N, Irani Z (2009) Impact of Employees of Psychological Change. European and Mediterranean Conference on Information Systems.

31. 31. Watters S (2009) Shared Leadership: Taking Flight. Journal of Nursing Administration, 39: 26-29.

32. McDaniel S (2012) Top 15 Characteristics of a Good Leader.

33. Kenkel P, Fitzwater B (2012)What makes an effective chair.

34. Harper T (2011) Lad like an Impartial Sleeper.

35. Bednarz T (2011) Leaders to Leader Five Ways to Establish Trust and Credibility.

36. Vesterinen S, Suhonen M, Isola A, Paasivaara L, Laukkala H, et al. (2013) Nurse Managers' Perceptions Related to their Leadership Styles, Knowledge and Skills in These Areas-A Viewpoint: Case of Health Center Wards in Finland. ISRN Nursing, pp: 1-8.

37. Leiter M (2006) Nursing Environments: Knowledge to Action. Final Report Submitted to Health Canada, Health Policy Research Program: Quality Workplaces for Health Professionals.

38. Nickline W (2001) Thank You aren't enough. Journal of Nurse Leadership 14: 15-8.

39. Rego A, Sousa F, Pina E, Cunha M, Correia A, et al. Leader Self-Reported Emotional Intelligence and Perceived Employee Creativity: An Exploratory Study. Creativity and Management, 16: 250-264.

40. Baxter C (2013) The Effect of Coaching on Nurse Manager Leadership of Unit Based Performance Improvement: Exploratory Case Studies. 